\title{
ESTUDO DA ESTABILIDADE DO ÁCIDO CLAVULÂNICO EM DIFERENTES CONDIÇÕES DE CRIOPRESERVAÇÃO.
}

\author{
Santos. D. Z. T. ${ }^{1}$, Gracindo. A ${ }^{1}$, Fonseca. G. A. ${ }^{1}$, Cerri, M. O. ${ }^{1}$ \\ ${ }^{1}$ Universidade Júlio de Mesquita Filho (UNESP), Departamento de Bioprocessos e \\ Biotecnologia. \\ E-mail para contato: marcel@fcfar.unesp.br
}

\begin{abstract}
RESUMO - Com o aumento de bactérias patogênicas resistentes a fármacos derivados de $\beta$-lactâmicos devido a produção de enzimas $\beta$-lactamases, muitos antibióticos tem se tornado ineficientes, gerando a necessidade de estudos para a inibição dessas enzimas. O ácido clavulânico produzido por Streptomyces clavuligerus consegue inibir essas enzimas, entretanto, ele é quimicamente instável na sua forma natural, sendo que esta estabilidade depende do $\mathrm{pH}$ e da temperatura. Esse projeto teve como objetivo a analise da estabilidade de ácido clavulânico quando armazenado após a sua produção. Ele foi armazenado em diferentes condições de temperatura, sendo que a que permitiu a sua maior conservação foi quando congelado a $-70^{\circ} \mathrm{C}$.
\end{abstract}

\section{INTRODUÇÃO}

Os antibióticos $\beta$-lactâmicos foram descobertos no inicio do século vinte o que representou um momento decisivo na luta contra bactérias patogênicas. Porém, o numero de bactérias patogênicas resistentes a fármacos derivados de $\beta$-lactâmicos cresceu, devido à produção de enzimas $\beta$-lactamases por esses microrganismos, que catalisam a hidrolise do anel $\beta$-lactâmico do antibiótico originando um produto sem ação antibacteriana. Então começaram estudos para a descoberta de um inibidor dessas enzimas e, assim, chegou-se ao ácido clavulânico (AC), produzido por Streptomyces clavuligerus, uma bactéria filamentosa e estritamente aeróbica. Sendo assim, a produção de AC tem despertado um grande interesse nas indústrias farmacêuticas do mundo de entender a bioquímica e a genética da sua biossíntese, assim como, aperfeiçoar métodos de separação e purificação (Silva, C.S.; 2010).

Geralmente se encontra AC em formulações junto com outros antibióticos $\beta$ lactâmicos sensíveis à ação de $\beta$-lactamases, tais como penicilina e cefalosporina, isso porque sua atividade antibacteriana é baixa quando comparada com outros antibióticos (Rodrigues, K.C.S.; 2015).

O AC é um metabólico secundário, ou seja, sintetizado na fase estacionária e acreditase que esteja envolvido com funções de sobrevivência na natureza. Apresenta estruturas moleculares mais complexas do que os compostos que o originam. É produzido por um processo fermentativo complexo e sofre a influência de vários parâmetros tais como $\mathrm{pH}$, temperatura, agitação, aeração, além de fontes de carbono, nitrogênio e indutores adequados. O consumo das fontes de carbono e nitrogênio resulta no acúmulo de diferentes metabólitos no caldo fermentativo, ocasionando a degradação do AC. Sendo assim, essas fontes tem bastante influência na produção de AC por Streptomyces clavuligerus (Rodrigues, K.C.S.; 2015). 
O AC é quimicamente instável na sua forma natural, pois ele contém um grupo carbonila ligado ao anel beta-lactâmico que é susceptível a hidrólise (Silva, C.S.; 2010), razão que explica seus processos de recuperação ter baixos rendimentos. Há uma menor degradação de AC em soluções aquosas do que em meio de fermentação, isso porque o meio tem outros componentes, tais como amônio (Rodrigues, K.C.S.; 2015). A taxa de degradação de AC é altamente dependente do $\mathrm{pH}$, já que normalmente ocorre uma menor degradação em soluções ácidas. A estabilidade diminui também com o aumento da temperatura (Silva, C.S.; 2010). Entretanto, como o uso do AC muitas vezes não ocorre imediatamente após a sua produção, se torna importante a análise de condições de armazenamento mais adequadas para que ocorra a menor degradação possível.

\section{MATERIAIS E MÉTODOS}

\subsection{Micro-organismo}

O micro-organismo utilizado neste trabalho foi o Streptomyces clavuligerus ATCC 27064 , conservado em criotubos na forma de células vegetativas a $-70^{\circ} \mathrm{C}$ suspensas em solução crioprotetora contendo $20 \%$ v/v de glicerol.

\subsection{Meios de cultura utilizados}

Foi utilizado o meio de cultura de reativação proposto por Rosa et al. (2005) composto por $15 \mathrm{~g} / \mathrm{L}$ de glicerol; $10 \mathrm{~g} / \mathrm{L}$ de peptona bacteriológica; $10 \mathrm{~g} / \mathrm{L}$ de extrato de malte; $1 \mathrm{~g} / \mathrm{L}$ de extrato de levedura; $21 \mathrm{~g} / \mathrm{L}$ de tampão MOPS; $2,5 \mathrm{~g} / \mathrm{L}$ de $\mathrm{K}_{2} \mathrm{HPO}_{4} ; 0,75 \mathrm{~g} / \mathrm{L}$ de $\mathrm{MgSO}_{4} .7 \mathrm{H}_{2} \mathrm{O}$ e $1 \mathrm{~mL} / \mathrm{L}$ de solução de sais.

O meio de cultura de crescimento teve a mesma composição do meio de cultura de produção, ambos baseados no meio proposto por Teodoro et al. (2006). Temos como composição desses meios $15 \mathrm{~g} / \mathrm{L}$ de glicerol; $20 \mathrm{~g} / \mathrm{L}$ de isolado proteico de soja; $21 \mathrm{~g} / \mathrm{L}$ de tampão MOPS; 0,8 g/L de $\mathrm{K}_{2} \mathrm{HPO}_{4} ; 0,75 \mathrm{~g} / \mathrm{L}$ de $\mathrm{MgSO}_{4} .7 \mathrm{H}_{2} \mathrm{O}$ e $1 \mathrm{~mL} / \mathrm{L}$ de solução de sais.

$\mathrm{O} \mathrm{pH}$ dos meios foi ajustado para 6,8 e a esterilização realizada em autoclave a $121^{\circ} \mathrm{C}$ por 15 minutos.

\subsection{Metodologia analítica para determinação da concentração de AC}

Para a determinação da concentração de ácido clavulânico foi utilizado o método espectrofotométrico proposto por Bird et al. (1982), que consiste na leitura espectrofotométrica no comprimento de onda de $311 \mathrm{~nm}$ do produto da derivatização do ácido clavulânico com o reagente imidazol. As absorbâncias obtidas pelo método foram inseridas na Equação 1 para calculo da concentração. 


\subsection{Testes realizados}

Foi realizado um cultivo para analisar a estabilidade de AC. O meio de reativação e de crescimento foram mantidos durante 24 horas a $30^{\circ} \mathrm{C}$ em béqueres de $250 \mathrm{~mL}$ sendo que somente $10 \%$ do volume foi utilizado e o de produção foi mantido por 72 horas a $28^{\circ} \mathrm{C} \mathrm{em}$ béqueres de $500 \mathrm{~mL}$ também com $10 \%$ do volume utilizado, todos em Shaker a 250 RPM.

Imediatamente após o termino da produção amostras foram centrifugadas a $4^{\circ} \mathrm{C}$ e 3720 RPM durante 15 minutos para que o produto de interesse (sobrenadante) fosse separado das células e então foi realizada uma quantificação de AC (item 2.3).

O restante das amostras foram armazenadas em diferentes condições de temperatura: algumas foram congeladas imediatamente em freezer a temperatura de $-18^{\circ} \mathrm{C}$ (amostras $\mathrm{A}$ ), outras foram congeladas imediatamente em freezer a temperatura de $-70^{\circ} \mathrm{C}$ (amostras $\mathrm{B}$ ) e outras foram congeladas a temperatura de $-18^{\circ} \mathrm{C}$ e após 24 horas transferidas para temperatura de $-70^{\circ} \mathrm{C}(\operatorname{amostras} \mathrm{C})$.

Após 4 dias foi feita a quantificação de AC das amostras congeladas em diferentes condições e posteriormente essas quantificações foram feitas de 7 em 7 dias durante 1 mês. Todas as análises foram realizadas em triplicata.

\section{RESULTADOS E DISCUSSÃO}

Após a realização dos testes, a partir das absorbâncias obtidas foi possível calcular a concentração de AC pela curva de calibração (Equação 1) nas diferentes temperaturas de conservação no decorrer dos dias, obtendo resultados que podem ser analisados na Figura 1 e na Tabela 1. 
Figura 1 - Gráfico da concentração de ácido clavulânico armazenado em diferentes condições com o decorrer do tempo.

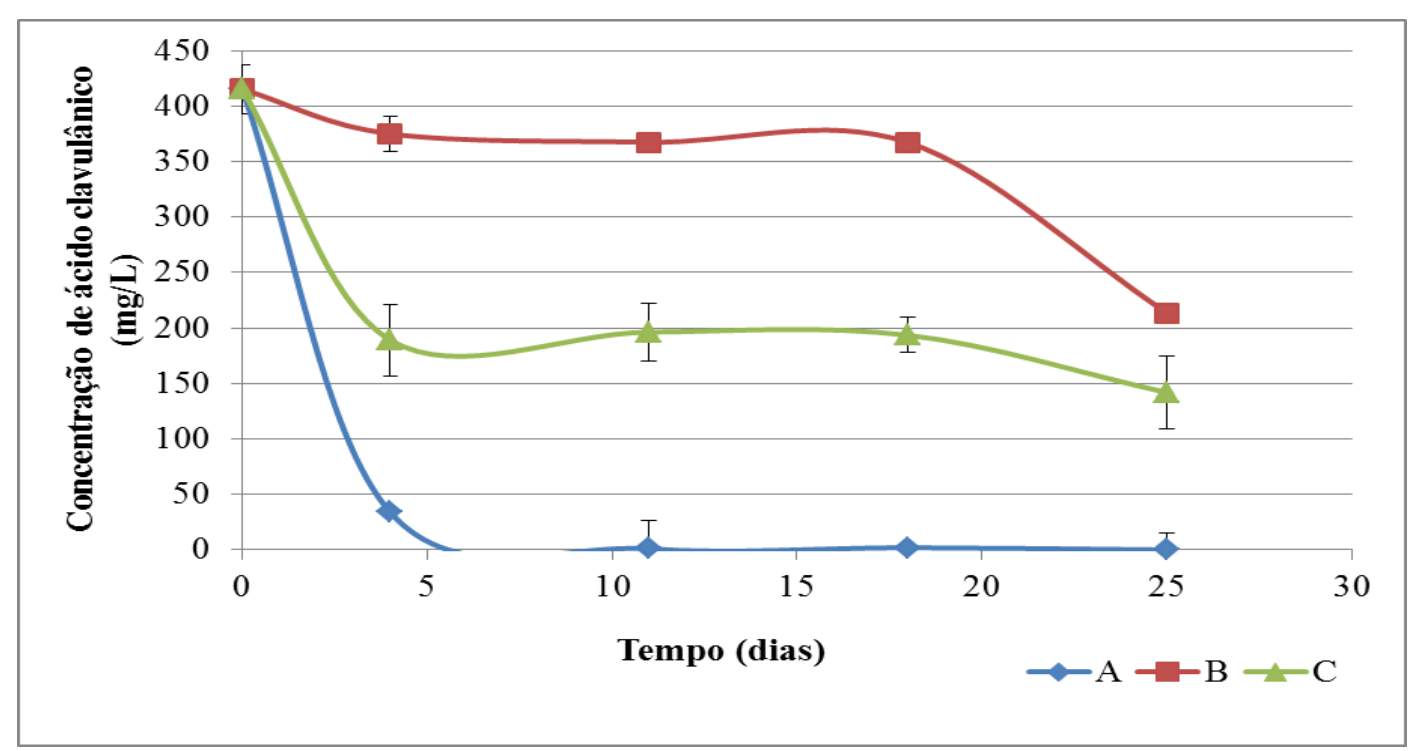

Tabela 1 - Porcentagem da concentração de AC com o decorrer do tempo.

\begin{tabular}{cccc}
\hline \multirow{2}{*}{ Dias } & \multicolumn{3}{c}{ \% da concentração de AC } \\
& A & B & C \\
\hline 0 & 100,0 & 100,0 & 100,0 \\
4 & 8,1 & 90,3 & 45,6 \\
11 & 0,2 & 88,5 & 47,3 \\
18 & 0,5 & 88,4 & 46,6 \\
25 & 0,0 & 51,5 & 34,2 \\
\hline
\end{tabular}

É possível observar pelo gráfico da Figura 1 que a condição de conservação que menos degrada AC com o tempo é a que, imediatamente após o término da produção, o AC foi armazenado a temperatura de $-70^{\circ} \mathrm{C}$ (amostras B). Até o quarto dia houve, de acordo com a Tabela 1, degradação de 9,7\% mas, após isso, essa degradação se torna relativamente estável, sendo que até o décimo oitavo dia houve degradação de apenas 1,9\% a mais de AC. Entretanto, após esse período, essa degradação se torna bem acentuada, sendo que em uma semana foi degradado mais $12,5 \%$ de AC.

Quando armazenado diretamente em $-18^{\circ} \mathrm{C}$ (amostras A) a degradação de AC é muito rápida sendo que em de 4 dias é degradado cerca de 91,8\% de AC como pode-se observar na Tabela 1, se tornando inviável o armazenamento a longo prazo nessa condição.

Ao ser realizada a transferência de $\mathrm{AC}$ de $-18^{\circ} \mathrm{C}$ para $-70^{\circ} \mathrm{C}$ em 24 horas (amostras $\mathrm{C}$ ) houve uma maior conservação da concentração, mas ainda sim o decaimento de $54,4 \%$ da concentração nos primeiros 4 dias pode ser considerado muito acentuado e, só partir do sexto dia ela se manteve relativamente estável. 


\section{CONCLUSÃO}

Observando os dados obtidos é possível concluir que, para garantir que ainda exista uma concentração de $\mathrm{AC}$ relativamente alta, ele deve ser armazenado em freezer $-70^{\circ} \mathrm{C}$. Entretanto, a sua utilização deve ser realizada em cerca de 15 dias pois, após isso, há uma degradação ainda maior de AC. Ainda assim, por haver um decréscimo de aproximadamente $10 \%$ nos 4 primeiros dias de armazenamento, é interessante que sua utilização seja feita o quanto antes, ainda mais se objetiva-se a sua utilização em processos onde grandes concentrações são perdidas, como a purificação, ou em larga escala, onde o decréscimo da concentração de AC representa uma grande perda econômica.

\section{REFERÊNCIAS}

BIRD, A.E.; BELLIS, J.M.; GASSON, B.C. Spectrophotometric assay of clavulanic acid by reaction with imidazole. Analyst, v.107, p.1241-1245, 1982.

RODRIGUES, K.C.S. Estudo da influência do pH e da temperatura na produção de ácido clavulânico por Streptomyces clavuligerus em biorreator convencional. Universidade Federal de São João Del-Rei, Ouro Branco - MG, 2015.

ROSA, J.C.; BAPTISTA NETO, A.; HOKKA, C.O.; BADINO, A.C. Influence of dissolved oxygen and shear conditions on clavulanic acid production by Streptomyces clavuligerus, Bioproc Biosyst Eng, v.27, p.99-104, 2005

SILVA, C.S. Purificação do ácido clavulânico por processo de filtração tangencial, extração por sistemas de duas fases aquosas e re-extração com resina de troca iônica. Universidade Federal de São Carlos, São Carlos - SP, 2010.

TEODORO, J.C.; BAPTISTA-NETO, A.; CRUZ-HERNÁNDEZ, I.L.; HOKKA, C.O.; BADINO-JR, A.C. Influence of feeding conditions on clavulanic acid production in fed-batch cultivation with medium containing glycerol. Appl Microbiol Biotechnol, v. 72, p.450-455, 2006. 